\title{
Peri-implantitis and Severity Level
}

\author{
Eser Elemek ${ }^{1}$ Omer Birkan Agrali² Bahar Kuru³ ${ }^{3}$ Leyla Kuru²
}

1 Private Practice, Istanbul, Turkey

2Department of Periodontology, Faculty of Dentistry, Marmara University, Istanbul, Turkey

${ }^{3}$ Department of Periodontology, Faculty of Dentistry, Yeditepe University, Istanbul, Turkey

Address for correspondence Eser Elemek, PhD. Private Practice, Istanbul, Turkey (e-mail: eserelemek@gmail.com).

Eur J Dent 2020;14:24-30

\begin{abstract}
Keywords

- marginal bone level

- peri-implant disease

- peri-implantitis

Objectives Different diagnostic criteria were used for diagnosis of peri-implant diseases. The aim of this cross-sectional study was to explore prevalence of peri-implant diseases and subclassify peri-implantitis based on different levels of radiographic and clinical findings.

Materials and Methods Two hundred patients having 655 dental implants were included in this study. In addition to clinical measurements, standard long-cone parallel technique was used to evaluate marginal bone level around implants. Following diagnosis of peri-implant diseases, peri-implantitis was further subclassified using a severity leveling in terms of marginal bone level and probing depth.

Results Mean age of 200 subjects was $52.8 \pm 12.2$ years and $63 \%$ were females. In total, bleeding on probing was present in $93 \%$ and suppuration in $27 \%$ of implants. On subject basis, $2.5 \%$ were diagnosed as healthy, $28 \%$ with peri-implant mucositis (PM), and $69.5 \%$ with peri-implantitis, whereas on implant basis, $3.6 \%$ were healthy, $36 \%$ presented PM, and $60.4 \%$ peri-implantitis. Furthermore, when severity leveling was applied, peri-implantitis prevalence changed markedly and ranged from 14.5 to $31.0 \%$ at the subject level and from 10.0 to $22.0 \%$ at the implant level. Subgingival restoration margins were observed in $70.6 \%$ of patients for implants with PM and in $44 \%$ patients for implants with peri-implantitis. Most of the implants with peri-implantitis were with platform match (71.5\%).

Conclusions Applying different thresholds to the peri-implantitis definition yielded different prevalence rates ranging from 10 to $31 \%$. As no established diagnostic criteria are being used today, results from clinical studies may not reflect the true disease prevalence.
\end{abstract}

\section{Introduction}

Dental implants have been a part of our lives since 1965 when studies of Branemark commenced. Today, ever increasing number of dental implants in total or partial edentulous patients provides an outstanding treatment alternative to conventional prosthetic rehabilitation all around the world. However, widespread use of dental implants has brought alone a gradually increasing condition called "disease of peri-implant tissues"1. Therefore, the treatment of peri-implant diseases has been an upmost importance. At first, interrelationship between dental implant and surrounding soft and hard tissues was needed to be clarified at molecular cellular and clinical level. ${ }^{2,3}$ To provide treatment for peri-implant disease, in the light of early studies, it has been realized that peri-implant lesions are very similar to periodontal lesions in terms of infectious and inflammatory characteristics. ${ }^{4}$ Therefore, dental professionals have attempted to treat peri-implant lesions using their experience and knowledge on periodontal diseases. ${ }^{5,6}$ However, as the incident of peri-implant diseases rose, clinicians were in need of classifying them.

In 1994, Albrektsson and Isidor ${ }^{1}$ proposed for the first time the definitions of two peri-implant diseases, as PM and peri-implantitis. PM was defined as a reversible inflammatory 
reaction in the soft tissues surrounding a functioning implant while peri-implantitis as inflammatory reactions associated with progressive loss of supporting bone. As the knowledge expanded over the years, Zitzmann and Berglundh ${ }^{7}$ revisited the descriptions where PM was defined as the presence of inflammation in the mucosa at an implant with no signs of supporting bone loss and peri-implantitis as the presence of supporting bone loss in addition to inflammation in the mucosa.

In the consensus report of the sixth European Workshop on Periodontology, in addition to descriptions proposed by Zitzmann and Berglundh, ${ }^{7}$ it was recommended that the extent as well as the severity (amount of bone loss) of peri-implant lesions are needed to be clarified. ${ }^{8}$ Taking this suggestion into account, Koldsland et $\mathrm{al}^{9}$ evaluated the severity of peri-implantitis in terms of different levels of radiographic bone loss and probing depth (PD) with the presence of bleeding on probing (BOP) and/or suppuration. Absence of a well-established definition for peri-implant diseases leads researchers to use several criteria in the clinical studies yielding to different conclusions which may result in misdiagnosis and confusion. Ferreira et $\mathrm{al}^{10}$ described $\mathrm{PM}$ as the presence of BOP and peri-implantitis as the presence of BOP and/or suppuration, pocket depth $\geq 5 \mathrm{~mm}$ associated with the presence of bone loss. Based on these definitions, they found a prevalence of 64.6 and $8.9 \%$ for PM and peri-implantitis, respectively. On the contrary, Renvert et al ${ }^{11}$ observed peri-implantitis prevalence as $63.7 \%$, taking into account the criterion of Sanz and Chapple ${ }^{12}$ who described peri-implantitis as peri-implant bone loss $>2 \mathrm{~mm}$ in association with clinical signs of inflammation.

The lack of widely accepted diagnostic criteria for peri-implant diseases with particular attention to PD and marginal bone level makes it difficult to interpret the results of published studies. Therefore, the aim of this study was to explore the prevalence of peri-implant diseases and subclassify peri-implantitis based on different levels of radiographic and clinical findings.

\section{Materials and Methods}

This cross-sectional study was conducted in consecutive 200 patients who applied to the Department of Periodontology, Dental Faculty, Marmara University, Istanbul, Turkey between October 2014 and December 2015. The study was approved by the Ethics Committee of the Marmara University (70737436-050.06.04-1400123324). Subjects $\geq 18$ years of age and having dental implants in function for at least 1 year were recruited. The implants had been placed either in private offices or at university clinics.

\section{Clinical Examination}

Demographic information regarding age, sex, history of periodontitis, and smoking habit were obtained from patients. Full mouth plaque index (PI), ${ }^{13}$ gingival index $(\mathrm{GI})^{14}$, and PD at six sites per tooth/implant were measured. PI and GI were measured on mesiobuccal, midbuccal, distobuccal, and midlingual surfaces around all teeth and implants. PD was also measured in mesiolingual and distolingual sites. Periodontal probe with a $0.5 \mathrm{~mm}$ diameter (University of North Carolina PCPUNC15, Hu Friedy Ins Co. A.B.D.) was used for clinical examination. Additionally, BOP, presence of suppuration, presence of midbuccal keratinized tissue, subgingival restoration margins, jaw of placement, mean function time, and implant-abutment interface were evaluated at implant sites. BOP was assessed as the presence/absence of bleeding observed 30 seconds after probing and calculated as percentage and suppuration as the discharge of pus immediately after probing.

\section{Radiographs}

The same clinician used standard long-cone parallel technique for the radiographic examination of all implants. A single researcher (E.E.) evaluated the implant-abutment interface and measured the distance between the reference point of implant platform level and the most apical bone in contact with the implant, both on mesial and distal sites. ${ }^{11}$ The site with the most pronounced bone loss was chosen to represent the marginal bone loss (MBL) around each implant. ${ }^{9,15}$ The ImageJ (Wayne Rasband; National Institute of Health; MD, United States) program was used for the analysis of peri-implant bone levels. Each periapical had a standard $1 \mathrm{~mm}$ marker (-Fig. 1). The distance was converted into millimeter by dividing the length of the defect into the length of the marker calculated by ImageJ program.

\section{Definitions}

Peri-implant health was defined as having no clinical signs of inflammation and $\mathrm{MBL}<2 \mathrm{~mm}$, PM as the presence of BOP and/or suppuration and $\mathrm{MBL}<2 \mathrm{~mm}$, peri-implantitis as the presence of BOP and/or suppuration and MBL $\geq 2 \mathrm{~mm}$ as proposed by the eighth European Workshop on Periodontology. ${ }^{12}$

Furthermore, peri-implantitis was further subclassified using a severity leveling in terms of MBL and PD as shown below:

- $\mathrm{MBL} \geq 2 \mathrm{~mm}$ at $\mathrm{PD} \geq 4$ and $\mathrm{PD} \geq 5 \mathrm{~mm}$

- $\mathrm{MBL} \geq 3 \mathrm{~mm}$ at $\mathrm{PD} \geq 4$ and $\mathrm{PD} \geq 5 \mathrm{~mm}$

- $\mathrm{MBL} \geq 4 \mathrm{~mm}$ at $\mathrm{PD} \geq 4$ and $\mathrm{PD} \geq 5 \mathrm{~mm}$

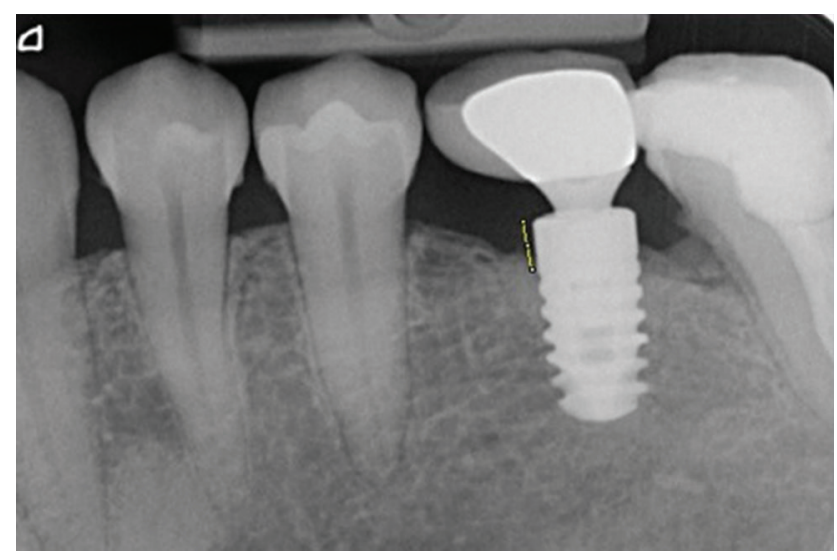

Fig. 1 Analysis of radiographic bone loss. 
According to these criteria, characteristics of the subjects, clinical and radiographic characteristics of peri-implant tissues in relation to peri-implant health and disease were evaluated. Additionally, prevalence of peri-implant health and diseases at subject and implant level were measured.

\section{Intraexaminer Calibration}

All the measurements were performed by an experienced clinician (E.E.). To assess the intraexaminer variability for radiographic measurements, the mesial sites of the first 25 implants and then 10 implants for each 50th implant were remeasured. ${ }^{9}$ A total of 150 implants were used for calibration. The intraclass correlation coefficient (ICC) was calculated as 0.87 . Furthermore, to assess intraexaminer variability for clinical measurements, PD (six sites/implant) of the first 25 implants were remeasured ${ }^{9}$ and ICC was calculated as 0.97 .

\section{Data Analysis}

The statistical analyses (SPSS v.15.0; SPSS, Chicago, IL, United States) included descriptive statistics (mean \pm standard deviation), Chi square, Kruskal-Wallis, and Mann-Whitney U tests for clinical and radiographic parameters. The data were evaluated both at subject and implant basis. The level of significance was set at $p<0.001$.

\section{Results}

\section{Subject Characteristics}

The mean age of 200 subjects included in the present study was $52.8 \pm 12.2$ years and $63 \%$ were females. Subjects with smoking habit were $22 \%$ and those who had a history of periodontitis constituted $64.5 \%$ of all. Registrations in relation to peri-implant health and disease are presented in - Table $\mathbf{1}$. According to the diagnostic criteria generated by Sanz and Chapple, ${ }^{12} 2.5 \%$ of the subjects were diagnosed as healthy, $28 \%$ with PM, and $69.5 \%$ with peri-implantitis.

\section{Implant Characteristics and Peri-implant Clinical and Radiological Conditions}

Out of 655 implants assessed in this study, $43.8 \%$ had been placed in the maxilla, $56.2 \%$ in the mandible (-Table 2 ). Eighteen percent of the implants were in an anterior position (13-23 and 33-43), whereas $92 \%$ had been placed in the premolar and molar region.
Clinical examination demonstrated that BOP was present in $93 \%$ and suppuration in $27 \%$ of the implants with a mean function time of $53.5 \pm 36.7$ months. The mean PD and MBL of the implants were $3.6 \pm 1.6$ and $3.0 \pm 2.6 \mathrm{~mm}$, respectively. Registrations in relation to peri-implant health and disease are presented in - Table 2. Mean PD and MBL for implants with peri-implantitis were found significantly higher compared with implants with PM $(p<0.001)$.

Majority of the implants observed were restorated with fixed prosthetics (96.9\%). Keratinized tissue was present at 64.9 and $57.8 \%$ of all implants and implants diagnosed with peri-implantitis, respectively. Subgingival restoration margins were observed in $54 \%$ of the implants, whereas it was 70.6\% for implants with PM and 44\% for implants with peri-implantitis. Implants with platform switch were $47.6 \%$ of all. However, most of the implants with peri-implantitis were with platform match $(71.5 \%)$ (- Table 2 ).

According to the previously mentioned diagnostic criteria (Sanz and Chapple ${ }^{12}$ ), 3.6\% of the implants were healthy, 36\% presented PM, and $60.4 \%$ peri-implantitis (-Table 3 ).

\section{Analysis of Prevalence at Subject and Implant Level using Different Diagnostic Criteria}

When peri-implant tissues were evaluated at subject and implant level according to Sanz and Chapple ${ }^{12}$ diagnostic criteria, occurrence of PM was found 28 and 36\%; peri-implantitis 69.5 and $60.4 \%$, respectively (-Table 3 ). Furthermore, when different levels of bone loss and PD parameters were added to the criteria, the finding of peri-implantitis prevalence changed markedly and ranged from 14.5 to $31 \%$ at subject level; from 10 to $22 \%$ at implant level as shown in (-Table 4).

\section{Discussion}

As recommended in the consensus report of the sixth European Workshop on Periodontology, ${ }^{8}$ a cross-sectional study design with implants placed both in university and private clinics was used in this study to obtain information on the effectiveness rather than efficacy of implant treatment. As most of the implant treatments are being performed in private dental clinics worldwide, our study may give a clear point of view and valid results about the prevalence of peri-implant diseases.

Table 1 Characteristics of the subjects with implants of which peri-implant tissues evaluated according to the criteria of Sanz and Chapple ${ }^{12}$

\begin{tabular}{|l|l|l|l|l|l|}
\hline \multirow{2}{*}{} & Total & Healthy & Peri-implant mucositis & Peri-implantitis & $\boldsymbol{p}$-Value \\
\cline { 2 - 6 } & $(\boldsymbol{n}=\mathbf{2 0 0})$ & $(\boldsymbol{n}=\mathbf{5 )}$ & $(\boldsymbol{n}=\mathbf{5 6})$ & $(\boldsymbol{n}=139)$ & \\
\hline Female gender (\%) & $126(63)$ & $4(80)$ & $39(69.6)$ & $83(59.7)$ & $0.31^{\mathrm{a}}$ \\
\hline Age (y) \pm SD & $52.8 \pm 12.2$ & $38.2 \pm 12.2$ & $49.5 \pm 9.1$ & $54.7 \pm 12.8$ & $0.01^{\mathrm{b}}$ \\
\hline Smoking habit (\%) & $44(22)$ & $2(40)$ & $12(21.4)$ & $30(21.6)$ & $0.61^{\mathrm{a}}$ \\
\hline History of periodontitis (\%) & $129(64.5)$ & $5(100)$ & $33(59)$ & $63(45.3)$ & $0.12^{\mathrm{a}}$ \\
\hline
\end{tabular}

Abbreviation: SD, standard deviation.

aPearson's Chi-square test.

'Kruskal-Wallis test. 
Table 2 Clinical and radiographic characteristics of peri-implant tissues in relation to peri-implant health and disease

\begin{tabular}{|c|c|c|c|c|c|}
\hline & Total & Health & $\begin{array}{l}\text { Peri-implant } \\
\text { mucositis }\end{array}$ & Peri-implantitis & $p$-Value \\
\hline \multicolumn{6}{|l|}{ Jaw of placement (\%) } \\
\hline Maxilla & 43.8 & 41.7 & 37.8 & 47.6 & $0.11^{\mathrm{b}}$ \\
\hline Mandible & 56.2 & 58.3 & 62.2 & 52.4 & $0.20^{\mathrm{b}}$ \\
\hline Mean function time $(\mathrm{mo}) \pm \mathrm{SD}$ & $53.5 \pm 36.7$ & $40.8 \pm 20.1$ & $42.1 \pm 30.8$ & $61.2 \pm 38.9$ & $0.31^{\mathrm{b}}$ \\
\hline BOP (\%) & $631(93)$ & - & $238(100)$ & $393(100)$ & $0.42^{\mathrm{a}}$ \\
\hline Suppuration (\%) & 177 & - & 46 (19) & $131(33)$ & $0.38^{\mathrm{a}}$ \\
\hline Mean PD $(\mathrm{mm}) \pm \mathrm{SD}$ & $3.7 \pm 1.6$ & $2.4 \pm 0.5$ & $3.2 \pm 0.7$ & $4.0^{c} \pm 1.8$ & $0.000^{\mathrm{b}}$ \\
\hline $\begin{array}{l}\text { Mean marginal bone loss } \\
(\mathrm{mm}) \pm \mathrm{SD}\end{array}$ & $3.0 \pm 2.6$ & $0.5 \pm 0.6$ & $0.8 \pm 0.7$ & $4.5^{c} \pm 2.2$ & $0.000^{\mathrm{b}}$ \\
\hline \multicolumn{5}{|l|}{ Prosthetic restoration type (\%) } & \multirow[t]{3}{*}{$0.42^{\mathrm{b}}$} \\
\hline Fixed & 96.9 & 100 & 99.1 & 95.6 & \\
\hline Overdenture & 3.1 & - & 0.9 & 4.4 & \\
\hline \multicolumn{5}{|l|}{ Keratinized tissue (midbuccal) (\%) } & \multirow[t]{3}{*}{$0.58^{\mathrm{b}}$} \\
\hline Present & 64.9 & 79.2 & 75.2 & 57.8 & \\
\hline Absent & 35.1 & 21.8 & 24.8 & 42.2 & \\
\hline \multicolumn{5}{|c|}{ Subgingival restoration margins (\%) } & \multirow[t]{3}{*}{$0.17^{b}$} \\
\hline Present & 54 & 54.2 & 70.6 & 44 & \\
\hline Absent & 46 & 45.8 & 29.4 & 56 & \\
\hline \multicolumn{5}{|l|}{ Implant-abutment interface } & \multirow[t]{3}{*}{$0.45^{b}$} \\
\hline Platform switch & 47.6 & 83.3 & 75.6 & 28.5 & \\
\hline Platform match & 52.4 & 16.7 & 24.4 & 71.5 & \\
\hline
\end{tabular}

Abbreviations: BOP, bleeding on probing; PD, probing depth; SD, standard deviation.

aPearson's Chi-square test.

'Kruskal-Wallis test.

${ }^{c} p<0.01$ different from peri-implant mucositis, Mann-Whitney $U$ test.

Table 3 Prevalence of peri-implant health and diseases at subject and implant levels

\begin{tabular}{|l|l|l|l|l|}
\hline & Total & Health & Peri-implant mucositis & Peri-implantitis \\
\hline Subject level (\%) & $200(100)$ & $5(2.5)$ & $56(28)$ & $139(69.5)$ \\
\hline Implant level (\%) & $655(100)$ & $24(3.6)$ & $238(36)$ & $393(60.4)$ \\
\hline
\end{tabular}

In this study, meeting the recommendation of using a cross-sectional study design and a study sample greater than 100 implant-treated subjects, ${ }^{8}$ clinical and radiological examinations were performed at 200 subjects having 655 implants similar to the other studies. ${ }^{11,16,17}$

Biofilm accumulating around natural teeth can also grow around dental implants and on peri-implant tissues causing infection..$^{18}$ While defining peri-implant inflammation, it is also important to discriminate bone loss due to infection and the one seen during remodeling. ${ }^{19}$ Hence, in studies analyzing peri-implant disease prevalence, a criterion of an implant in function at least for 1 year is accepted. . $^{1520,21}$ Therefore, only implants in function at least for 1 year were included for the analysis.

The mean age of patients with healthy implants was 38.2 years in our study. By the increase in age, peri-implant situation worsened from PM to peri-implantitis which was statistically significant $(p<0.01)$. In a study by Renvert et al, ${ }^{11}$ 172 patients with a mean age of 68.2 years were analyzed and age was found as a risk factor for peri-implantitis. In another study by Marrone et al, ${ }^{22}$ peri-implantitis was found to be more in a group of people older than 65 years. Parallel to our findings, age is considered as a risk factor for the development of peri-implant diseases.

Cigarette smoking has been identified as a risk indicator in several studies, ${ }^{23,24}$ causing the vasoconstruction of the vessels and decrease the nutrition of the tissues. In our study, only $22 \%$ of patients were smokers, which makes it difficult to interpret the results.

History of periodontitis was found to be a significant risk factor for the development of peri-implant diseases ${ }^{8,25,26}$. Out of 200 patients included in this study, $64.5 \%$ were found to have a history of periodontitis. Van der Weijden et $\mathrm{al}^{27} \mathrm{cal}-$ culated the implant success over 5 years in patients with and 
Table 4 Changes in the prevalence of peri-implantitis when different criteria were applied

\begin{tabular}{|c|c|c|c|c|c|c|}
\hline & BOP $( \pm)$ & $\mathrm{PD}(\mathrm{mm})$ & Bone loss (mm) & $n$ & $\%$ & $p$-Value \\
\hline \multicolumn{7}{|l|}{ Subject level } \\
\hline & + & $\geq 4$ & $\geq 2$ & 62 & 31 & \multirow[t]{6}{*}{$0.000^{\mathrm{a}}$} \\
\hline & + & $\geq 5$ & $\geq 2$ & 29 & 14.5 & \\
\hline & + & $\geq 4$ & $\geq 3$ & 55 & 27.5 & \\
\hline & + & $\geq 5$ & $\geq 3$ & 29 & 14.5 & \\
\hline & + & $\geq 4$ & $\geq 4$ & 42 & 21 & \\
\hline & + & $\geq 5$ & $\geq 4$ & 37 & 18.5 & \\
\hline \multicolumn{7}{|l|}{ Implant level } \\
\hline & + & $\geq 4$ & $\geq 2$ & 143 & 22 & \multirow[t]{6}{*}{$0.000^{\mathrm{a}}$} \\
\hline & + & $\geq 5$ & $\geq 2$ & 70 & 11 & \\
\hline & + & $\geq 4$ & $\geq 3$ & 126 & 19 & \\
\hline & + & $\geq 5$ & $\geq 3$ & 69 & 10.5 & \\
\hline & + & $\geq 4$ & $\geq 4$ & 92 & 14 & \\
\hline & + & $\geq 5$ & $\geq 4$ & 63 & 10 & \\
\hline
\end{tabular}

Abbreviations: BOP, bleeding on probing; $n$, number; PD, probing depth.

aPearson's Chi-square test.

without a history of periodontitis, and they observed more peri-implant bone loss and implant failures in patients with a history of periodontitis. In a systematic review by Karoussis et $\mathrm{al}^{28}$ increased PD and peri-implant bone loss were also found around implants placed in patients with a history of periodontitis. Although a high number of patients were with a history of periodontitis in our study, we did not find any correlation in peri-implant health and disease. This may be explained by the discrepancy between numbers of the healthy $(n=5)$ and peri-implant disease ( $n=56$ for PM and $n=139$ for peri-implantitis) groups.

Roos-Jansåker et $\mathrm{al}^{29}$ investigated the role of keratinized mucosa in peri-implant disease and found no association between the absence of keratinized mucosa and disease progression. Wennström and Derks ${ }^{30}$ analyzed the literature if there was a need for keratinized mucosa to maintain health and tissue stability but concluded that the current evidence was limited and weak. Keratinized mucosa was present in $64.9 \%$ of all implants in this study. However, when implants with peri-implantitis were further analyzed in relation to presence of keratinized mucosa, there was no significant difference between health and disease which makes it difficult to interpret the results as mentioned in previous studies. ${ }^{29,30}$

In the 11th Workshop of Periodontology, ${ }^{31}$ for the primary prevention of peri-implant diseases, it was recommended that "if cemented implant restorations have been selected, the restoration margins should be located at the mucosal margin to allow meticulous removal of excess cement and clinicians also have to be aware that implant placement at a submucosal level (to hide crown margins) may carry a higher risk for peri-implant diseases"31. In our study, 70.6\% of implants diagnosed with PM had subgingival restoration margins confirming the risk of peri-implant disease. On the other hand, the presence of subgingival restoration margins decreased to $44 \%$ for implants with peri-implantitis. This finding may be explained by the MBL followed by gingival recession observed in most of the peri-implantitis cases.

Farronato et $\mathrm{al}^{32}$ found less MBL around platform switch implants as compared with platform match implants. Finelle et $\mathrm{al}^{33}$ assessed the effect of different design healing abutments on marginal bone level and observed horizontal bone apposition on the implant shoulder of implants with narrow healing abutments (platform switch) concluding that "the configuration of transmucosal component directly influences marginal bone level." In our study, 83.3\% of healthy implants and $75.6 \%$ of implants with PM had platform switch designs. On the other hand, $71.5 \%$ of implants diagnosed with peri-implantitis had platform match designs corroborating the results of other studies. ${ }^{32,33}$

In this study, the definitions of peri-implant health and disease followed the recommendations of the consensus report of the eighth European Workshop on Periodontology as the initial radiographs of the patients were not present. ${ }^{12}$ Our aim was to explore the prevalence of peri-implant diseases and subclassify peri-implantitis based on different levels of radiographic and clinical parameters. The prevalence of peri-implantitis was found to be 69.5 and $60.4 \%$ at subject and implant level, respectively. However, with the inclusion of different PD and MBL levels, peri-implantitis prevalence dramatically decreased to between 14.5 and $31 \%$ at subject level and between 10 and $22 \%$ at implant level. So far, studies analyzing the prevalence of peri-implant diseases have yielded conflicting results , $^{7,11,17}$ which can be explained by the use of different thresholds for diagnosis. Thus, the prevalence rates of peri-implant diseases that have been claimed until today may be controversial.

Mir-Mari et al $^{15}$ observed PM as $21.6 \%$ at implant level among subjects who were under strict maintenance program. On the other hand, in our study, PM was found $36 \%$ at 
implant level. None of the subjects included in our study sample followed a periodontal/peri-implant maintenance program, which may explain the higher PM prevalence rates.

According to the recommendations in consensus report by Lindhe and Meyle, ${ }^{8}$ when there is more than one implant in a single patient, the one with more inflammation should be considered to describe the patient level peri-implant disease. As the other studies in the literature, we calculated the patient level peri-implant disease according to these criteria. This may explain the high percentage of subject level peri-implantitis (69.5\%) in our study.

Jemt and Johansson ${ }^{34}$ observed MBL $\geq 3 \mathrm{~mm}$ only in $1.3 \%$ of the implants. Koldsland et $\mathrm{al}^{9}$ using the same level of MBL to define peri-implantitis reported the prevalence $8.2 \%$ at implant level. However, when they added PD value $\geq 4 \mathrm{~mm}$ into the criteria, peri-implantitis prevalence decreased to $6 \%$. In our study, when $\mathrm{PD} \geq 4 \mathrm{~mm}$ and $\mathrm{MBL} \geq 3 \mathrm{~mm}$ were considered, the prevalence of peri-implantitis was found to be $19 \%$ at implant level. Defining peri-implantitis as PD $\geq 4 \mathrm{~mm}$ and MBL $\geq 2 \mathrm{~mm}$, Koldsland et $\mathrm{al}^{9}$ observed the prevalence of peri-implantitis as 20.4 and $11.4 \%$ at subject and implant levels, respectively, whereas in this study, the corresponding values were 31 and $22 \%$, when the same definition was used and further subclassification was performed. The size of our study sample both at subject and implant level was approximately twice higher as compared with the study of Koldsland et al, ${ }^{9}$ which gave rise to statistically significant difference. Additionally, all of the implants observed by Koldsland et $\mathrm{al}^{9}$ were placed in a university environment while our study sample consisted of implants placed both in university and private clinics which reflects high clinical significance.

In the presence of initial radiographs taken right after implant placement, the analysis of peri-implant health and disease can be studied much more precise. Because we analyzed patients having implants placed in advance, it was one of the limitations of our study that we could not compare them with the initial radiographs as they may have had the bone resorption during the osseointegration period. Also, we were unable to know that whether the implants were placed angulated or if they had machined collar surface which some clinicians leave supracrestally. All these parameters may cause the miscalculation of peri-implant bone level and PD resulting in different prevalences.

In conclusion, in the present study, the prevalence of PM was found to be 28 and $36 \%$ and that of peri-implantitis to be 69.5 and $60.4 \%$ at subject and implant levels, respectively. However, applying different thresholds to the peri-implantitis definition yielded different prevalence rates ranging from 10 to $31 \%$. Since no established diagnostic criteria are being used today, results from clinical studies may not reflect the true disease prevalence. There is a need for revision of peri-implant disease criteria with the addition of subclassification system. Today, to treat periodontal diseases, we diagnose and classify them. Therefore, with a precise definition of peri-implant diseases, the treatment protocol for PM and peri-implantitis can be generalized and more effective for all the population in the same way we have been doing for periodontal diseases.

\section{Clinical Relevance}

In the absence of clinical signs of inflammation, clinicians can diagnose peri-implant health. However, it is not the same to define a peri-implant disease as there are so many patients and implant-based factors yielding different results.

\section{Funding}

None.

\section{Conflict of Interest}

None declared.

\section{References}

1 Albrektsson T, Isidor F. Consensus report of session IV. In: Lang NP, Karring T, eds. Proceeding of the 1st European Workshop on Periodontology. London: Quintessence Publishing; 1994:365-369

2 Zitzmann NU, Berglundh T, Marinello CP, Lindhe J. Experimental peri-implant mucositis in man. J Clin Periodontol 2001;28(6):517-523

3 Berglundh T, Gislason O, Lekholm U, Sennerby L, Lindhe J. Histopathological observations of human periimplantitis lesions. J Clin Periodontol 2004;31(5):341-347

4 van Winkelhoff AJ, Goené RJ, Benschop C, Folmer T. Early colonization of dental implants by putative periodontal pathogens in partially edentulous patients. Clin Oral Implants Res 2000;11(6):511-520

5 Renvert S, Roos-Jansåker AM, Claffey N. Non-surgical treatment of peri-implant mucositis and peri-implantitis: a literature review. J Clin Periodontol 2008;35(8, Suppl):305-315

6 Heitz-Mayfield LJ, Lang NP. Comparative biology of chronic and aggressive periodontitis vs. peri-implantitis. Periodontol 2000 2010;53:167-181

7 Zitzmann NU, Berglundh T. Definition and prevalence of peri-implant diseases. J Clin Periodontol 2008;35(8, Suppl): 286-291

8 Lindhe J, Meyle J; Group D of European Workshop on Periodontology. Peri-implant diseases: consensus report of the sixth european workshop on periodontology. J Clin Periodontol 2008;35(8, Suppl):282-285

9 Koldsland OC, Scheie AA, Aass AM. Prevalence of peri-implantitis related to severity of the disease with different degrees of bone loss. J Periodontol 2010;81(2):231-238

10 Ferreira SD, Silva GL, Cortelli JR, Costa JE, Costa FO. Prevalence and risk variables for peri-implant disease in Brazilian subjects. J Clin Periodontol 2006;33(12):929-935

11 Renvert S, Aghazadeh A, Hallström H, Persson GR. Factors related to peri-implantitis - a retrospective study. Clin Oral Implants Res 2014;25(4):522-529

12 Sanz M, Chapple IL; Working Group 4 of the VIII European Workshop on Periodontology. Clinical research on periimplant diseases: consensus report of Working Group 4. J Clin Periodontol 2012;39(Suppl 12):202-206

13 Silness J, Löe H. Periodontal disease in pregnancy. II. Correlation between oral hygiene and periodontal condtion. Acta Odontol Scand 1964;22:121-135

14 Loe H, Silness J. Periodontal disease in pregnancy. I. Prevalence and severity. Acta Odontol Scand 1963;21:533-551

15 Mir-Mari J, Mir-Orfila P, Figueiredo R, Valmaseda-Castellón E, Gay-Escoda C. Prevalence of peri-implant diseases. A cross-sectional study based on a private practice environment. J Clin Periodontol 2012;39(5):490-494

16 Aguirre-Zorzano LAR, Estefanía-Fresco R, Telletxea O, Bravo M. Prevalence of peri-implant inflammatory disease in patients with a history of periodontal disease who receive 
supportive periodontal therapy. Clin Oral Implants Res 2015;26(11):1338-1344

17 Konstantinidis IK, Kotsakis GA, Gerdes S, Walter MH. Crosssectional study on the prevalence and risk indicators of periimplant diseases. Eur J Oral Implantology 2015;8(1):75-88

18 Lang NP, Berglundh T; Working Group 4 of Seventh European Workshop on Periodontology. Periimplant diseases: where are we now?-consensus of the seventh European workshop on periodontology. J Clin Periodontol 2011;38(Suppl 11):178-181

19 Mombelli A, Müller N, Cionca N. The epidemiology of periimplantitis. Clin Oral Implants Res 2012;23(6, Suppl 6):67-76

20 Roos-Jansåker AM. Long time follow up of implant therapy and treatment of peri-implantitis. Swed Dent J Suppl 2007;188(188):7-66

21 Serino G, Turri A, Lang NP. Probing at implants with periimplantitis and its relation to clinical peri-implant bone loss. Clin Oral Implants Res 2013;24(1):91-95

22 Marrone A, Lasserre J, Bercy P, Brecx MC. Prevalence and risk factors for peri-implant disease in Belgian adults. Clin Oral Implants Res 2013;24(8):934-940

23 Karbach J, Callaway A, Kwon YD, d'Hoedt B, Al-Nawas B. Comparison of five parameters as risk factors for peri-mucositis. Int J Oral Maxillofac Implants 2009;24(3):491-496

24 Rinke S, Ohl S, Ziebolz D, Lange K, Eickholz P. Prevalence of periimplant disease in partially edentulous patients: a practice-based cross-sectional study. Clin Oral Implants Res 2011;22(8):826-833

25 Heitz-Mayfield LJ. Peri-implant diseases: diagnosis and risk indicators. J Clin Periodontol 2008;35(8, Suppl):292-304

26 Passariello C, Di Nardo D, Testarelli L. Inflammatory periimplant diseases and the periodontal connection question. Eur J Dent 2019;13(1):119-123
27 Van der Weijden GA, van Bemmel KM, Renvert S. Implant therapy in partially edentulous, periodontally compromised patients: a review. J Clin Periodontol 2005;32(5):506-511

28 Karoussis IK, Kotsovilis S, Fourmousis I. A comprehensive and critical review of dental implant prognosis in periodontally compromised partially edentulous patients. Clin Oral Implants Res 2007;18(6):669-679

29 Roos-Jansåker AM, Lindahl C, Renvert H, Renvert S. Nine- to fourteen-year follow-up of implant treatment. Part II: presence of peri-implant lesions. J Clin Periodontol 2006;33(4):290-295

30 Wennström JL, Derks J. Is there a need for keratinized mucosa around implants to maintain health and tissue stability.? Clin Oral Implants Res 2012;23(6, Suppl 6):136-146

31 Jepsen S, Berglundh T, Genco R, et al. Primary prevention of peri-implantitis: managing peri-implant mucositis. J Clin Periodontol 2015;42(Suppl 16):S152-S157

32 Farronato D, Santoro G, Canullo L, Botticelli D, Maiorana C, Lang NP. Establishment of the epithelial attachment and connective tissue adaptation to implants installed under the concept of "platform switching": a histologic study in minipigs. Clin Oral Implants Res 2012;23(1):90-94

33 Finelle G, Papadimitriou DEV, Souza AB, Katebi N, Gallucci GO, Araújo MG. Peri-implant soft tissue and marginal bone adaptation on implant with non-matching healing abutments: micro-CT analysis. Clin Oral Implants Res 2015;26(4):e42-e46

34 Jemt T, Johansson J. Implant treatment in the edentulous maxillae: a 15-year follow-up study on 76 consecutive patients provided with fixed prostheses. Clin Implant Dent Relat Res 2006;8(2):61-69 